\title{
Clinical decision making regarding the use of vital signs in physical therapy
}

Virginia G. Thistle', Allison L. Basskin', Eric Shamus ${ }^{2 *}$ and Renee Jeffreys-Heil ${ }^{3}$

*Correspondence: eshamus@fgcu.edu

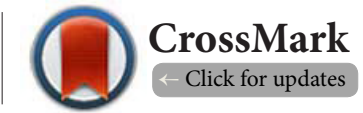

'Graduate Physical Therapist, Florida Gulf Coast University, USA.

2Department of Rehabilitation Sciences, College of Health Professions and Social Work, Florida Gulf Coast University, USA.

${ }^{3}$ RCEP, Assistant Professor, Florida Gulf Coast University, USA.

\begin{abstract}
Background: Vital signs including body temperature, blood pressure, heart rate, respiratory rate, and pulse oximetry are components of the clinical decision making process by physical therapists. Vital signs help to predict physical therapy indications, contraindications and outcomes. Previous studies have shown that physical therapists do not always objectively measure vital signs each visit.

Objectives: The purpose of the study was to examine the clinical decision making process involved in the measurement of vital signs by physical therapists.

Design: This study was a qualitative design utilizing a questionnaire with three sections including demographic data, clinical decision making questions, and two risk-based scenarios in which participants were asked to indicate whether or not they would assess vital signs.

Methods: Seventeen practicing physical therapists were given a questionnaire by phone, email, or in person. Data were recorded, coded, and transcribed. Answers to open ended questions were grouped into themes based on common responses and similar characteristics.

Results: The primary factors cited in response to source of reference for cardiovascular risk included clinical experience, education, and patient presentation. The primary factors provided in response to the decision to treat or refer based on abnormal vital signs included patient history, clinical experience, various parameters, and contacting the physician.

Conclusion: The variation of factors that influenced the decision making process by the participants may be reflective of the lack of guidelines and the broad understanding of the need and benefit of objectively assessing vital signs.
\end{abstract}

Keywords: Vital signs, physical therapy, blood pressure, heart rate, exercise

\section{Introduction}

Physical Therapists are autonomous practitioners [1]. Measuring vital signs including temperature, blood pressure, heart rate, respiratory rate, and pulse oximetry allows physical therapists to screen for red flags, monitor a patient's cardiovascular response to exercise, incorporate relevant information into the plan of care and use the information gained for making clinical predictions. According to the American Physical Therapy Association' Guide to Practice, measurement of blood pressure, heart rate, respiratory rate, and pulse oximetry are appropriate to characterize or quantify cardiovascular and pulmonary signs and symptoms as part of an assessment of aerobic capacity and endurance [2].

Physical therapists do not always measure vital signs every visit [3]. Moreover, unlike many physiological parameters, core body temperature in particular is poorly monitored [4]. Whether physical therapists should be measuring vital signs every visit should not be controversial, as patients' status can undergo changes from day to day that are not visible or easily communicated. Retrospective studies have shown that critical vital signs often do not appear within the first 24 hours of hospital admission indicating the need for periodic reevaluation [4]. 
Thistle et al. Physical Therapy and Rehabilitation 2016,

In addition, evaluation and treatment of many dysfunctions commonly involves physical exertion which can increase stress on the patient's different body systems $[5,6]$.

The decision to take vital signs is a component of clinical decision making for physical therapists, which is multi-factorial in nature and can include factors such as the physical therapists themselves, the nature of the decision, and the context in which the decision occurred [7]. Vital signs should be implemented into a comprehensive risk evaluation rather than examined solely as a screening tool for clinical deterioration [8]. Currently, risk stratification guidelines are available through the American College of Sports Medicine which may be of variable familiarity to physical therapists $[9,10]$. Evidence on clinical decision making in relation to vital signs is not widely available in the existing literature. It is therefore important to know which factors influence the decision to take vital signs.

The purpose of the study was to examine the clinical decision making process involved in the measurement of vital signs by physical therapists including body temperature, blood pressure, heart rate, respiratory rate [11], and pulse oximetry. This study sought to answer the question, "What factors most strongly influence the decision of physical therapists to take vital signs?"

\section{Subjects and methods}

A questionnaire was created by the researchers and peer reviewed by two faculty members of the College of Health Professions and Social Work at Florida Gulf Coast University (FGCU). The questionnaire included a consent form and statement of confidentiality in accordance with the model provided by the Institutional Review Board (IRB) at FGCU. IRB approval was obtained before participant recruitment and data collection.

\section{Sampling strategy}

The study was a phenomenological design with snowball sampling to include 10 to 20 physical therapists. Recruitment was achieved through multiple sources including through Doctor of Physical Therapy faculty at FGCU as well as through participants themselves. Each participant was required to be a licensed and currently practicing physical therapist in the State of Florida, and only participants meeting these eligibility requirements were asked to participate. Participants were instructed not to proceed with the interview if they were not currently practicing or had been practicing for less than six months.

\section{Data collection}

Data collection consisted of an interview that was recorded, coded, and transcribed. The first part of the interview featured demographic questions. The second part featured a questionnaire related to clinical decision making (See Appendix 1). The third part included two clinical scenarios in which participants explained the reasoning behind their decisions whether or not to take vitals.

\section{Data analysis}

Answers to open ended questions were grouped into themes based on common responses and similar characteristics noted.

\section{Results \\ Qualitative results}

A total of 17 physical therapists were interviewed for this study including five through email and 12 either by phone or in person Tables 1-3.

Table 1. Years in physical therapy practice.

\begin{tabular}{ll}
\hline Range of Years & Number (\%) of Respondents \\
\hline Less than 5 years & $3(17.6 \%)$ \\
5-10 years & $4(23.5 \%)$ \\
11-20 years & $4(23.5 \%)$ \\
21-30 years & $5(29.4 \%)$ \\
Greater than 30 years & $1(5.9 \%)$ \\
\hline
\end{tabular}

Table 2. Highest level of education.

\begin{tabular}{ll}
\hline Degree in Physical Therapy & Number (\%) of Respondents \\
\hline Doctoral & $9(52.9 \%)$ \\
Masters & $6(35.3 \%)$ \\
Bachelors & $2(11.8 \%)$ \\
$21-30$ years & $5(29.4 \%)$ \\
Greater than 30 years & $1(5.9 \%)$ \\
\hline
\end{tabular}

Table 3. Practice setting.

\begin{tabular}{ll}
\hline Setting & Number (\%) of Respondents \\
\hline Outpatient & $15(88.2 \%)$ \\
Pediatrics & $1(5.9 \%)$ \\
Home health & $1(5.9 \%)$ \\
\hline
\end{tabular}

Decision to take vital signs on the first scenario patient The following is the first scenario that was given to the participants: "Patient is a 65 year old female who is referred to you for balance retraining following a fall. She was seen by her primary care physician two days ago. Patient has a history of hypertension and gastroesophageal reflux disease (GERD). Medications include propranolol (Inderal) and omeprazole (Prilosec), patient states that she is compliant with her medications." The respondents were then asked, "Would you take vital signs on this patient, if so which ones? Why or why not?"

Seven of the seventeen participants (41.2\%) stated that they would take blood pressure, $6 / 17$ participants $(35.3 \%)$ stated that they would take heart rate, $3 / 17$ participants (17.6\%) stated that they would take respiratory rate, $5 / 17$ participants (29.4\%) stated that they would take pulse oximetry, and 1/17 participant (5.9\%) that they would take temperature Table 4. Dependent upon on certain additional stipulations suggested by participants which were not specified in the scenario, $7 / 17$ 
Thistle et al. Physical Therapy and Rehabilitation 2016,

Table 4. APTA membership.

\begin{tabular}{ll}
\hline Membership & Number (\%) of Respondents \\
\hline Members & $9(60.0 \%)$ \\
Non-members & $8(47.1 \%)$ \\
\hline
\end{tabular}

participants (41.2\%) stated that they would take blood pressure, $6 / 17$ participants (35.3\%) stated that they would take heart rate, $2 / 17$ participants $(11.8 \%)$ stated that they would take respiratory rate, and $4 / 17$ participants $(23.5 \%)$ stated that they would take pulse oximetry. As stated by the participants:

"I would take blood pressure if primary care physician visit two days prior showed high blood pressure and it is something that needs monitoring."

"No, I probably would not. I would want to find out why she fell, if it's because she passed out, and if so I would want to do blood pressure. If the patient is sitting here looking in distress, I would certainly take heart rate and grab the blood pressure cuff. I would not take temperature. Respiratory rate and pulse oximetry I would take if she seemed like she was in distress."

"I probably would not right off the bat because there's a lot of time pressure unfortunately and so taking vital signs is quick but in a patient like her if she's feeling fine and has blood pressure normally under control, compliant with medications, hasn't done anything out of the ordinary, that's not a big red flag. So because of time pressure there wasn't anything that led me to it right off the bat."

Decision to take vital signs on the second scenario patient The following is the second scenario that was given to the participants: "Patient is a 16 year old male who is in the last stages of rehab following an $\mathrm{ACL}$ reconstruction. He is seeing you today to prepare for his return to football next week, so you plan to do advanced plyometric training."The respondents were then asked, "Would you take vital signs on this patient, if so which ones? Why or why not?"

Two of the seventeen participants (11.8\%) stated that they would take heart rate and one participant (5.9\%) stated an intention to take respiratory rate Table 5 . With additional stimulations not provided in the scenario, 2/17 participants $(11.8 \%)$ cited that they would take blood pressure, heart rate, and respiratory rate. None of the seventeen participants stated an intention to assess pulse oximetry on the patient. As stated by the participants:

"I would not take vital signs unless the patient is symptomatic for chest pain, shortness of breath, or dizziness/lightheadedness. Patient is a 16 year old male playing a highly intensive cardio sport program. Although he has been rehabbing his $\mathrm{ACL}$ for the past 2 to 3 months (more sedentary lifestyle) in preparation for return to sports, a 16 year old male has to be medically cleared to play football and have his physical in the first place. That would mean his primary care physician did not notice any concerns in regards to his cardiovascular
Table 5. Vital Signs for First Scenario Patient.

\begin{tabular}{ll}
\hline Vital Sign & Number (\%) of Respondents \\
\hline Blood pressure & $7(41.2 \%)$ \\
Heart rate & $6(35.3 \%)$ \\
Respiratory rate & $3(17.6 \%)$ \\
Pulse oximetry & $5(29.4 \%)$ \\
Temperature & $1(5.9 \%)$ \\
\hline
\end{tabular}

system. Unless I've noticed any new symptoms while rehabbing this patient prior to the plyometric program, I don't see it as a priority at this time for any vital signs."

"That's a good question because often times in the outpatient clinic, typically a lot of therapists don't take vitals but I would because if we're going to be doing advanced exercises, plyometrics are going to have an increased demand on the heart and so I would take pre and post vitals to assess the patient's tolerance. I would probably just take the heart rate and if there was any reason why I was worried I would assess their blood pressure. Since they're 16 years old I have to be honest we're not as cautious but maybe we should be."

"No. I don't think that it is necessary to take vitals as long as the patient is under the care of a primary care physician."

"Possibly respiratory rate/heart rate depending on response to exercise or as a way to teach him to work in a submax zone safely."

"I would not take vital signs on this patient-the textbook answer is that I should but honestly I probably wouldn't. I would not take it for reasons of time, equipment, and the athlete is young and otherwise presumed healthy."

\section{Source of reference for cardiovascular risk}

Participants were asked the question, "What is your source of reference when assessing cardiovascular risk?" Several themes emerged with regards to source of reference including ACSM guidelines, clinical experience, physician's protocol, education, patient presentation, criteria proposed by the cardiopulmonary section of the APTA, and facility policies and procedures.

\section{Clinical experience}

Clinical experience was cited by 5/17 (29.4\%) participants as a source of reference for cardiovascular risk. As stated by one of the participants:

"Clinical presentation-the entire clinical picture. This comes from experience; I don't go back and check the numbers. Patients that vitals were taken on displayed dizziness, and one had pacemaker issues."

"Clinical experience and we have policies and procedures that are too high or too low. If I'm not sure, I rely on clinical judgement and check the internet. It's not a big thing that was taught or emphasized in school."

\section{Education}

Education was cited by $3 / 17$ (17.6\%) participants as a source of reference for cardiovascular risk. As stated by one of the participants: 
Thistle et al. Physical Therapy and Rehabilitation 2016,

"I treat vestibular patents sometimes so I frequently take vitals with any patient that has orthostatic hypotension to determine if their blood pressure is appropriate. I will take vitals if the patient is having any adverse reaction in the clinic like hypoglycemia, shortness of breath, not feeling well, or needing to sit and rest more than they usually would. Based on my education background-learned a lot of that in schooland learned more about what's appropriate since I graduated."

\section{Patient presentation}

Patient presentation was cited by $12 / 17$ (70.6\%) participants as a source of reference for cardiovascular risk. As stated by one of the participants:

"Based on past medical history or symptoms seen. The hospital has specific cutoffs where if they're over this amount you're not allowed to treat them. Past medical history can include cardiovascular history or complex medical history. Tend to do on patients maybe 60 and up 100\% of the time."

\section{Factors influencing decision to treat or refer}

Participants were asked the question, "With a result of abnormal vital signs, what influences your decision to either treat or refer?" A variety of factors appeared to influence the decision to treat or refer a patient, including patient history and presentation, ACSM guidelines, clinical experience, and parameters set forth by various sources. Most respondents agreed that there is no definitive protocol in place when determining whether to treat or refer the patient.

\section{Patient history}

Patient history and presentation was cited by 6/17 (35.3\%) participants as a factor influencing their decision to treat or refer the patient. As stated by one of the participants:

"Based on symptoms-if uncomfortable in other ways, tired, feeling lightheaded, if they're sweating or have a headache, based on history of blood pressure issues, or recent change in medication that could be causing it. Or if I know they have a medical history that's a little bit tenuous. No company standard but I sort of have my own from class notes-kind of limitationsnot using cut and dry method but based on individual decision."

\section{Clinical experience}

Eight of the seventeen participants (47.1\%) cited clinical experience as an influential factor for their clinical decision to treat or refer the patient with abnormal vital signs. As stated by one of the participants:

"Clinical decision making-someone may have very low blood pressure but if on medication and if they're having active symptoms, for example sweating profusely, I may be more apt to do it. If they're acting fine, I may not be as likely. The whole clinical picture is what is relied on."

\section{Parameters}

Various parameters were cited as influential by 5/17 (29.4\%) participants. As stated by one of the participants:

"If mildly to moderately elevated, I will repeat after rest, watch them during exercise and take vitals to see their response. If above our cutoffs we're required to send them to the emergency room or call emergency services. Cutoffs I think are only for blood pressure and there is one for pulse but I don't know the numbers-it's posted on the wall and I don't have to deal with it much".

\section{Contact the physician}

With a result of abnormal vital signs, 5/17 (29.4\%) participants explicitly mentioned the referring physician as a source of influence with regards to decision making. As stated by one of the participants:

"Knowing the patient-if you have a good feel for that and if it doesn't feel right recommend they see family doctor. Lot of times I will give the family doctor a heads up and see which way they want to go. Textbook is $120 / 80$ but everyone is a little different-if I know from history that something is going on and they're not acting right then I recommend strongly seeing the physician and if significant enough I call the doctor too."

\section{Discussion}

Based on the findings of this study, the authors determined that vital signs are not performed in all patient scenarios. Vitals signs can provide insight to how a patient is performing and what the progression for the patient should look like. With direct access, patients can see a physical therapist without a referral for physical therapy. This autonomy warrants further evidence to guide the clinical decision making process by physical therapists with regard to assessment of vital signs. With the prevalence of undiagnosed cardiovascular disease and the impact of exercise on the cardiovascular system, physical therapists must understand the important implications of taking vital signs for purposes of safety and best practice decision making.

One instance that may jeopardize patient safety is by challenging the cardiovascular system without assessment of vital signs in an individual who is non-compliant with blood pressure medications. For instance, if the physical therapist is aware that the patient is on medication for high blood pressure and discovers normal vital signs on the initial evaluation, the physical therapist may assume that the patient's blood pressure is stable and defer regular assessment of vital signs during subsequent sessions. The underlying assumption in this situation, however, is that the patient will be compliant with the correct dosage of medication between sessions. If this is not the case and subsequent measurement is not taken, the stress to the patient's cardiovascular system may result in a cardiovascular incident.

Another potential compromise to patient safety is to falsely assume that a patient who is young is necessarily healthy. For instance, an athlete who is receiving pressure from outside sources to accelerate his rehabilitation and return to sport 
more rapidly may utilize performance enhancing substances. Furthermore, even if the physical therapist screens for the use of these substances, it may be difficult to confirm usage by the patient. These medications can have effects on the cardiovascular system and therefore may alter patient response to exercise and potentially increase the risk of an adverse event [12].

\section{Limitations}

The findings represent a small sample of physical therapists from Florida and it cannot be assumed that they represent the entire practice of physical therapy. With the question, "How often do you take vital signs?" some participants gave percentages while others gave specific numbers which may have impacted the data. Follow up questions were not asked to participants who provided answers through email. The question "What is your source of reference when assessing cardiovascular risk" required elucidation for certain individuals which may have affected bias in the answers provided.

\section{Conclusion}

Physical therapists need to understand the complexities of the patient they are evaluating and treating. This study demonstrated that vital signs are not always being monitored and objectively quantified. It is recommended by the authors that during the evaluation and treatment process it is imperative to monitor vital signs. Unfortunately, it may take a patient injury or patient collapse before some physical therapists realize the importance of vital signs. Future studies need to examine and better stratify risk factors for different conditions to better determine when exercise and activity maybe at risk.

Additional files

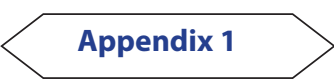

\section{Competing interests}

The authors declare that they have no competing interests.

\section{Authors' contributions}

\begin{tabular}{|l|c|c|c|c|}
\hline Authors' contributions & VT & AB & ES & RJH \\
\hline Research concept and design & $\checkmark$ & $\checkmark$ & $\checkmark$ & $\checkmark$ \\
\hline Collection and/or assembly of data & $\checkmark$ & $\checkmark$ & $\checkmark$ & $\checkmark$ \\
\hline Data analysis and interpretation & $\checkmark$ & $\checkmark$ & $\checkmark$ & $\checkmark$ \\
\hline Writing the article & $\checkmark$ & $\checkmark$ & $\checkmark$ & $\checkmark$ \\
\hline Critical revision of the article & $\checkmark$ & $\checkmark$ & $\checkmark$ & $\checkmark$ \\
\hline Final approval of article & $\checkmark$ & $\checkmark$ & $\checkmark$ & $\checkmark$ \\
\hline Statistical analysis & $\checkmark$ & $\checkmark$ & $\checkmark$ & $\checkmark$ \\
\hline
\end{tabular}

Publication history

Editor: Martin Grabois, Baylor College of Medicine, USA. Received: 18-Oct-2016 Final Revised: 15-Nov-2016

Accepted: 01-Dec-2016 Published: 15-Dec-2016

\section{References}

1. Domholdt $E$ and Durchholz AG. Direct access use by experienced therapists in states with direct access. Phys Ther. 1992; 72:569-74. | Article I PubMed

2. American Physical Therapy Association. Guide to Physical Therapist Practice. Alexandria, VA: American Physical Therapy Association. 2014.

3. Peters J. Measurement of HR and BP in the Outpatient Orthopedic Setting. Unpublished manuscript, Florida Gulf Coast University, Fort Myers, FL. 2014.

4. Harries AD, Zachariah R, Kapur A, Jahn A and Enarson DA. The vital signs of chronic disease management. Trans R Soc Trop Med Hyg. 2009; 103:537-40. | Article | PubMed

5. Fletcher GF, Balady GJ, Amsterdam EA, Chaitman B, Eckel R, Fleg J, Froelicher VF, Leon AS, Pina IL, Rodney R, Simons-Morton DA, Williams MA and Bazzarre T. Exercise standards for testing and training: a statement for healthcare professionals from the American Heart Association. Circulation. 2001; 104:1694-740. | Article | PubMed

6. Laird WP, Fixler DE and Huffines FD. Cardiovascular response to isometric exercise in normal adolescents. Circulation. 1979; 59:651-4. | Article | PubMed

7. Smith $\mathrm{M}$, Higgs $\mathrm{J}$ and Ellis $\mathrm{E}$. Physiotherapy decision making in acute cardiorespiratory care is influenced by factors related to physiotherapist and the nature and context of the decision: a qualitative study. Aust $J$ Physiother. 2007; 53:261-7. | Article | PubMed

8. Lighthall GK, Markar S and Hsiung R. Abnormal vital signs are associated with an increased risk for critical events in US veteran inpatients. Resuscitation. 2009; 80:1264-9. | Article | PubMed

9. ACSM. ACSM's Guidelines for Exercise Testing and Prescription, 9e. Philadelphia, PA: Lippincott Williams \& Williams. 2014.

10. Scherer SA, Noteboom JT and Flynn TW. Cardiovascular assessment in the orthopaedic practice setting. J Orthop Sports Phys Ther. 2005; 35:730-7. | Article | PubMed

11. Cretikos MA, Bellomo R, Hillman K, Chen J, Finfer S and Flabouris A. Respiratory rate: the neglected vital sign. Med J Aust. 2008; 188:657-9. | Article I PubMed

12. Ram CV. Beta-blockers in hypertension. Am J Cardiol. 2010; 106:1819-25. | Article | PubMed

\section{Citation:}

Thistle VG, Basskin AL, Shamus E and Jeffreys-Heil R. Clinical decision making regarding the use of vital signs in physical therapy. Phys Ther Rehabil. 2016; 3:7. http://dx.doi.org/10.7243/2055-2386-3-7 